\title{
Prevalence and Related Factors of Common Mental Disorder Among Individual Nusantara Sehat (NSI) Staff in Remote Primary Health Care
}

\author{
Syachroni $^{1 *}$, Rosita $^{1}$, Mimi Sumiarsih ${ }^{1}$, In Nurlinawati ${ }^{1}$, Rudi H. Putranto ${ }^{1}$ \\ ${ }^{I}$ Center of Research and Development for Health Resources and Services, Ministry of Health, Jakarta, Indonesia \\ "Corresponding author. Email: syachroni_1987@yahoo.com
}

\begin{abstract}
Data from the national health survey (Riskesdas), Ministry of Health Republic of Indonesia showed there's increasing the proportion of risk common mental disorders (CMD) in people aged $>15$ years from 6.0\% (in 2013) to $9.8 \%$ (in 2018). This study is to determine the prevalence of CMD among health worker after joined as individual Nusantara Sehat (NSI) staff di remote primary health care and also to determine the relationship between socio-demographic factors, work stressors, and CMD. A cross-sectional study involving the target population NSI in remote primary health care was conducted on December 2018. A socio-demographic, the 20-item self-reporting questionnaire (SRQ), the 30 item-survey diagnostic stress (SDS) questionnaire were self-administered. The presence of CMD was considered when the subject answers "yes" to 6 statements or more in SRQ-20. The $\chi 2$ test was used to analyze data statistically. In total, 449 NSI staff participated in the study. Generally, the prevalence of CMDs among NSI staff was $21.4 \%(n=96)$. Nurses are known to tend to have a lower prevalence while the dentists tend to have the highest prevalence compared with other group types of health worker in terms of CMD. The results of statistical tests showed that marital status has a significant affect to CMD ( $<<0.05)$ and 5 from 6 stressors were assessed was statistically associated with CMD ( $\mathrm{p}<0.01)$. Intervention for NSI is needed to restore their mental health conditions in order to better working conditions. An in-depth analysis of the causes of stress is needed, especially in the health workers with high CMD to reduce work stressors. As an addition, Ministry of Health should develop a coping stress management guidelines for health workers and strengthened stress monitoring implementation to support sustainable health services in remote areas.
\end{abstract}

Keywords: common mental disorder, health worker, SRQ-20, SDS, NSI

\section{INTRODUCTION}

Indonesia Act Number 18/2014 states mental health is a condition when individuals can develop physically, mentally, spiritually, and socially so that realizes skills to cope with stress, work productively, and to contribute to the community. Based on this Act, mental health can be a factor in quality of human resources besides physical, balanced nutrition, and socio-cultural. Mental emotional disorder is a condition that indicates psychological changes in an individual. It can be experienced by everyone on the condition of psychological distress. This disorder can manifest as symptoms of depression, psychosomatic disorders, and anxiety meanwhile common mental disorders (CMD) are characterized by insomnia, fatigue, irritability, forgetfulness, difficulty concentrating, and somatic complaints [1]. Mental health problems are also a problem that greatly affects productivity and health quality, both individual and community. Mental disorders if not addressed properly, it will get worse, thus, they becoming a public health problem and affected the family, society, and nation [2]. As additions, mental disorders not only affect job performance but other aspects of work, including the quality of interaction with patients and fellow colleagues [3]. Nowadays, CMD also represent the fourth leading cause of disability worldwide, as it represents the most prevalent disorder in the world population [4,5]. CMD present high prevalence among general populations and workers in particular with important individual and social consequences. Data from the Basic Health Research (Riskesdas), the prevalence of mental emotional disorders in Indonesia reached 6.0 percent in 2013 and increased significantly to 9.8 percent in 2018 $[6,7]$.

Recent studies have shown that mental illnesses have brought great harm to the professionals in health care area. The prevalence of depression among health care workers varies significantly when considering different groups such as between medical doctors or nursing staff or using different scales to assess depression. The prevalence of work-related stress among health careworkers (HCWs) estimated in Amsterdam that showed 
about $22 \%$ of HCWs had general stress, $17 \%$ had workrelated fatigue, $12 \%$ were distressed, and $6 \%$ burned out in 2016. Two previous studies in Brazil showed the prevalence CMD among 257 health professionals including mental health professionals and community health agents was 25.2-48.6\% [2].

A high level of occupational stress in various health and community service professions has been reported globally. Dealing with human suffering, the demands of a large job, and low recognition, work processes and long shift of these professionals and labor costs, making them increasingly vulnerable that lead to potential cause stress at work. Work stress, indirectly can have various consequences for workers, such as physiological, psychological and behavioral disorders. Stress experienced by continuously and cannot be controlled properly, will lead to burnout is a combination of physical exhaustion, psychological, and emotional [8].

The Ministry of Health of the Republic of Indonesia through the Minister of Health's Regulation regarding the special assignment of health workers in supporting the Nusantara Sehat. Nusantara Sehat is one of the programs in the context of fulfilling access, strengthen health services in terms of distribution and equity of health workers throughout Indonesia. Nusantara Sehat has two sub programs, individualbased Nusantara Sehat (NSI) and the team-based Nusantara Sehat (NST) which distinguishes the two programs is the placement system, wherein NS-based team consists of at least 5 types of health professionals in every health center, while NS individual only comprise at least one. The goals of this program was to achieve the highest degree of health, especially in the DTPK (remote, undeveloped, border and island) areas. In 2017, the NSI program has implemented and mobilized 1,663 health professionals in 612 primary health care (locus) in 161 districts/cities in 28 provinces in Indonesia with remote, underdeveloped, border and island areas.

In light of problems, increasing prevalence CMD in Indonesian population, variety of work stress, and the large number of health professionals participating in the NSI program has attracted the attention of researchers. Therefore, this study had two aims: to assess the prevalence of CMD between health professional's link to NSI program and to investigate whether their characteristics and work stressors associated with presence of CMD is. Addressing the prevalence of CMD and associated factors is expected to reduce this disorder among the health sector working population that will improve productivity.

\section{METHOD}

This is a cross-sectional study among health professionals working in remote areas. The target population consisted of NSI (Nusantara Sehat Individual) staff in the PHC, the following professions: medical doctors, dentist, nurse, midwife, pharmacist/pharmacist assistant, public health personnel, environmental health personnel, nutritionist, and medical laboratory personnel that occurred in December 2018. NSI staff were invited to respond to online instruments using self-administered questionnaires facilitated by the Board for Development and Empowerment Human Resources of Health, Ministry of Health Republic of Indonesia (Badan PPSDMK). Health Professionals who voluntarily agreed to participate were included in the study. As the data collection was conducted through a self-report instrument, the professionals received information about where to seek individual assistance if necessary.

The instrument used was consisting of sociodemographic, type of health professionals, and duty period. Aspects related to psychological well-being were assessed with the 20 item-Self Report Questionnaire (SRQ-20) for the present of CMD investigation and the work stressors of role impropriety on workers analysis using 30 itemSurvey Diagnostic Stress (SDS-30) instrument. The SRQ-20 and SDS-30 are globally recommended by the World Health Organization (WHO), both for community and PHC studies settings.

The SRQ-20 composed of 20 item questions on psychosomatic symptoms for tracking non-psychotic disorders, including depression, anxiety symptoms, and somatic complaints. SRQ assessment is done by giving a value of 0 for "no" or 1 for "yes", for each question. A value of 1 indicates the presence of symptoms in the last month, while the value of 0 indicates no symptoms, then the values are summed. The cut-off point used is 6 , the same method with Riskesdas analysis. Work stress questionnaire (SDS) consists of 30 questions include role conflict, role ambiguity, qualitative workload, quantitative workload, relationship with career development and responsibility to others. Respondents answered each question on a 1-7 Likert scale. Number 1 means that the question never causes stress, and for the next score up to number 7 which means it always causes stress. Assessment is done by adding up the answers to each work stressor point. The results of the sum of each work stressor item can be presented mild if the total score is under 10, moderate 10-20 and severe above 20. Statistical analysis were performed using the chi-square $(\chi 2)$ test. Differences between groups were considered statistically significant when $\mathrm{p}<$ 0.05 .

\section{RESULTS AND DISCUSSION}

In total, 582 NSI staff to participate in the study and 
no one refused. The percentage of incomplete data was $22.9 \%(n=133)$, thus producing a sample of 449 individuals respondent. The female participants represented $59.9 \%$ of the sample size (Table 1) including $18.2 \%$ married participants and $81.8 \%$ unmarried. Distribution of the data showed that $12.7 \%$ of the samples were nurses, $6.2 \%$ were medical doctors, $9.4 \%$ were dentist, and $84.4 \%$ were of other health professionals (Figure 1). The mean of months of experience as NSI was 12.05 with an SD of 2.8 months. The minimum number of the months of experience was 0 and the maximum number of the months of experience was 15 months. The majority of the sample was unaccompanied with NST in PHC $(95.8 \%)$ (Table 1).

Table 1. The relationship between socio-demographic and CMD among NSI staff $(\mathrm{n}=449)$

\begin{tabular}{|c|c|c|c|}
\hline \multirow{2}{*}{ Variables } & \multicolumn{2}{|c|}{ CMD Tendency Frequency, $n(\%)$} & \multirow[t]{2}{*}{$p$} \\
\hline & $(-)$ & $(+)$ & \\
\hline \multicolumn{4}{|l|}{ Sex } \\
\hline Male & $149(82.8)$ & $31(17.2)$ & 0.101 \\
\hline Female & $204(75.8)$ & $65(24.2)$ & \\
\hline \multicolumn{4}{|l|}{ Marital Status } \\
\hline Single & $265(76.1)$ & $83(23.9)$ & 0.026 \\
\hline Married & $88(87.1)$ & $13(12.9)$ & \\
\hline \multicolumn{4}{|c|}{ Working Experience } \\
\hline$\leq 12$ months & $194(75.5)$ & $63(24.5)$ & 0.079 \\
\hline$>12$ months & $159(82.8)$ & $33(17.2)$ & \\
\hline \multicolumn{4}{|l|}{ NST in PHC } \\
\hline Present & $12(63.2)$ & $7(36.8)$ & 0.087 \\
\hline Absent & $341(79.3)$ & $89(20.7)$ & \\
\hline
\end{tabular}

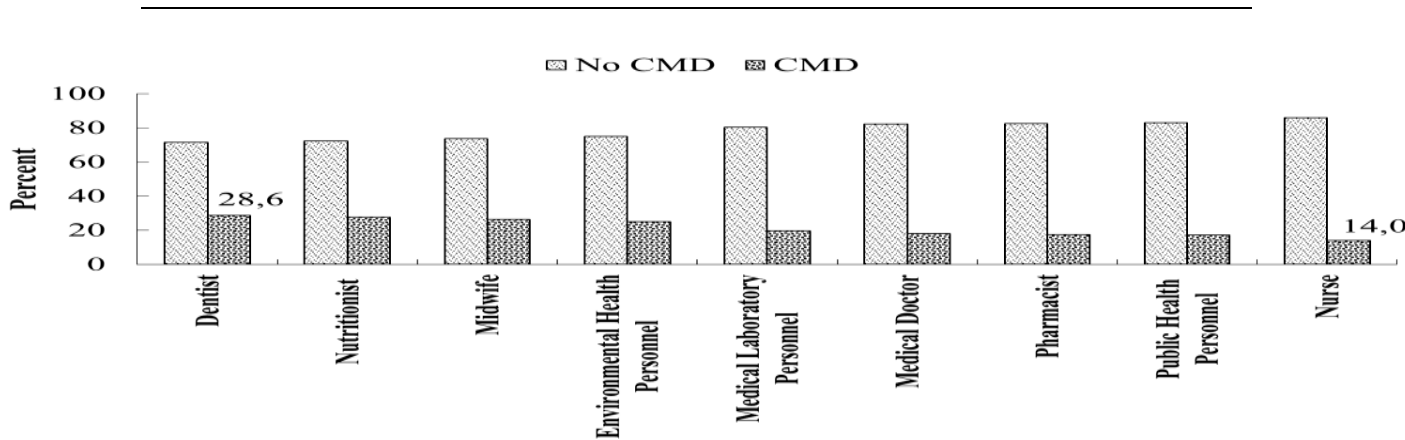

Figure 1. The prevalence rates of CMD among NSI staff $(n=449, p>0.05)$

The main outcomes of the study sample according to self-report questionnaire (SRQ-20) showed that there were about $21.4 \%$ of the NSIs who had CMD. The prevalence of CMD in female participants $(24.2 \%)$ was higher than males $(17.2 \%)$ but it was statistically insignificant $(\mathrm{p}=0.101)$. In addition, it was found that the singles had a higher rate of CMD (23.9\%) while married had $12.9 \%$ which was statistically significant with a p-value 0.026. There's no significant difference between working experience and present NST in PHC with CMD. Regarding to the health professional's type, it was found that the dentist reported highest experience CMD (28.6\%) than the medical doctors (17.9\%) and the nurse reported lowest experience CMD (14.0\%) with a p-value 0.567 (Figure 1). One of the factors that affected CMD was the work of stress. The results of this study showed that NSI personnel in remote areas experience stress moderate to severe. In this sample, all work-related issues were contribute to CMD. Thus, it was found that career development factors $(p=0.000)$, role overload quality $(\mathrm{p}=0.000)$, role overload quantity $(\mathrm{p}=0.000)$, role conflict $(\mathrm{p}=0.000)$, and role ambiguity $(\mathrm{p}=0.001)$ related to CMD. This results also indicate that work stress is significantly associated with CMD than socio-demographic factors. However, work stress on the responsibility factor does not have a significant relationship with NSI personnel (Table 2). 
Table 2. The relationship between work stressor and CMD among NSI staff $(n=449)$

\begin{tabular}{|c|c|c|c|c|}
\hline \multicolumn{2}{|c|}{ Work Stress Factor } & \multicolumn{2}{|c|}{$\begin{array}{l}\text { CMD Tendency } \\
\text { Frequency, } n(\%)\end{array}$} & \multirow[t]{2}{*}{$p$} \\
\hline & & $(-)$ & $(+)$ & \\
\hline \multirow[t]{3}{*}{ Responsibility for People } & Mild & $35(83.3)$ & $7(16.7)$ & 0.214 \\
\hline & Moderate & $234(80.1)$ & 58 (19.9) & \\
\hline & Severe & $84(73.0)$ & $31(27.0)$ & \\
\hline \multirow[t]{3}{*}{ Career Development } & Mild & $135(88.8)$ & $17(11.2)$ & 0.000 \\
\hline & Moderate & $199(77.7)$ & $57(22.3)$ & \\
\hline & Severe & $19(46.3)$ & $22(53.7)$ & \\
\hline \multirow[t]{3}{*}{ Role Overload Quality } & Mild & $72(88.9)$ & $9(11.1)$ & 0.000 \\
\hline & Moderate & $253(80.1)$ & $63(19.9)$ & \\
\hline & Severe & $28(53.8)$ & $24(46.2)$ & \\
\hline \multirow[t]{3}{*}{ Role Overload Quantity } & Mild & $71(86.6)$ & $11(13.4)$ & 0.000 \\
\hline & Moderate & $252(80.3)$ & $62(19.7)$ & \\
\hline & Severe & $30(56.6)$ & $23(43.4)$ & \\
\hline \multirow[t]{3}{*}{ Role Conflict } & Mild & $131(89.1)$ & $16(10.9)$ & 0.000 \\
\hline & Moderate & $207(74.5)$ & $71(25.5)$ & \\
\hline & Severe & $15(62.5)$ & $9(37.5)$ & \\
\hline \multirow[t]{3}{*}{ Role Ambiguity } & Mild & $172(86.0)$ & $28(14.0)$ & 0.001 \\
\hline & Moderate & $171(74.0)$ & $60(26.0)$ & \\
\hline & Severe & $10(55.6)$ & $8(44.4)$ & \\
\hline
\end{tabular}

International reviews have demonstrated high levels of occupational stress in various health and community service professions. Decades of research documents a multitude of workplace stressors and their impact on various outcomes measures, such as productivity, quality of healthcare service and worker health and wellbeing [9]. Unfortunately, studies of mental health related to this, especially health care workers tend to be poorly investigated in Indonesia. However, stress studies among health workers more likely been conducted in hospital-based settings than in community-based settings. To the best our knowledge, this is the first study to investigate the prevalence of common mental disorders among health workers in a remote health care area and the association of these disorders with sociocharacteristics and work-related factors.

The trend prevalence of CMD among the NSI was $21.4 \%$, higher than mental disorders than the average Indonesian population based on National Basic Health Survey in 2018. This number was equivalent with previous study, the prevalence of CMD found (16.2\%) among primary care health professionals of the Brazilian Northeast and South [10]. Braga et al. [2] suggest the high prevalence of CMD in primary health care work conditions are contributive factors to workers' illness. The relatively high prevalence rates of the CMD might theoretically be affected by the several potential factors and be bound to be suited to working in remote health systems, in a cross cultural context; dispersed and often highly mobile populations; serving populations with relatively high health needs; a physical environment of climatic extremes. Furthermore, related to sociodemography Idaiani et al. [11] stated personal variables are known to play a role in causing mental illness both mild to severe such as gender, marital status and residence whereas the prevalence of stress (neurosis) is more common in rural areas $(\mathrm{OR}=1.4 ; 95 \% \mathrm{CI}=1,155$ 1,858).

NSI program as special assignment of individual health workers is a special assignment whose placement is in the form of individuals which is adjusted to the mapping of workforce determined by the Ministry of Health in remote area to provide and coordinate a diverse range of health care services for remote, disadvantaged or isolated populations. Working in remote area commonly required to use a broad range of clinical skills in response to varied client needs. Their practice is guided by primary health care principles and includes emergency services, clinical care, health promotion and public health services [9]. Thereof, the working conditions aren't always as expected, and so the professionals cannot meet the needs of patients in their health that's might run into frustration. This situation oftentimes can also lead to mental disorders [12,13]. On the other hand, based on one study about assessing the level of understanding and ability of health workers to recognize, manage and prevent mental disorders in mental disorders revealed are still low. These low mental health literacy among professionals can influence the process of care and management of patients [14]. In earlier research, self-report data revealed sources of job dissatisfaction and reasons for attrition, but of particular relevance were the most displeasing workforce factors for the remote area [15].

Theoretically, employed women have a tendency more susceptible to experiencing mental disorders than men. In this study the number of respondents and the occurrence of mental disorders was dominated by female; majority of healthcare professionals especially nurses and midwife. These results are consistent with the 
theory that emotional mental disorders tendencies more about the individual with the female gender whereas more irritable, very sensitive, and includes feelings while men are more rational and do not accentuate his feelings [16]. Apart from the possibility of biological factors itself, pressure factors faced by women also make it easier to experience emotional mental disorders. Regarding correlation marital status to CMD among NSIs, singles had a higher rate of CMD (23.9\%) while married tend to be lower (12.9\%), which was statistically significant. This phenomenon could be explained in terms of lack of support for singles to share their problems. Similar with this study, single status health care workers in National Guard Hospital in Riyadh, KSA in 2018 has higher portion of initial diagnosis of depression while married $(p=0.05)$ [17]. A study who studied among the nurse who work in a psychiatric ward/mental hospital sum up unmarried as the most dominant stressors on the incidence of mental emotional disorders tendency ( $\mathrm{OR}=12.92 ; \mathrm{p}=0.003)$ [18]. People with unmarried status more often experience work stress because of the many tasks, difficulty adapting to environment, and having problems in interpersonal relationships. In contrast to married status, risk of stress triggered more likely not only focused on work but also complex problem, increasing life needs, and families [19].

Although the sample consisted of health professionals, these groups were quite different in terms of social demographic characteristics, and also, with regard to aspects related to work. In this current study, it was found that the dentist has highest prevalence in CMD than other health professional; nurse was lowest ones. In this study also, it was observed that nurses better adapt to work problems, health issues arising from work and with a lower prevalence of mental disorders compared to dentists. Similar to our result, Ludermir et al. [20] concluded higher education of health professional can contributed to psychological distress due to their lower pay, poorer working conditions, and access to living conditions can lead to stress and insecurity, causing psychological mechanisms of CMD. The previous studies among the dentists, occupational environment including inadequate examination rooms and dental unit to operate were the main risk factors that affect to stress $(\mathrm{OR}=1.11 ; \mathrm{p}=0.037)$ [21]. In general, factors that the dentists tend to have more physical workloads that can cause fatigue are performing light maintenance and sterilizing dental equipment. In terms of pathophysiology, the dentists will also experience complaints of low back pain and headaches that can lead stress at work [22]. Therefore, this result need for future investigations, through longitudinal studies to diagnose the actual prevalence and/or incidence of CMD among the dentist and the causal pathway needs to be highlighted.

Jobs are the number one cause of stress and a major impact on the welfare of the community. Several studies indicated that CMD have an impact on their quality of work. Other studies either investigated the relationship between mental health and its association with work stress factor. Working in disadvantage area are also mainly required to endure inadequate staffing levels, mandatory on-call duties and frequent overtime, professional isolation, limited supervision, low concerns for personal safety, inadequate infrastructure or equipment and issues arising from inter-cultural factors [23]. Similar with our findings, in this cross-sectional study it was found that the most of the factors that cause CMD in NSI are related to work. Our findings, work stressors is dominated by the work overload, both quality either quantity, role of ambiguity, followed by the role conflict and career development. This incident were possible because health workers in NSI program are requested to carry out the entire work despite the unclear role that is required to be able to carry out all processes including service to the patient, community, and improvement of management at the PHC. In earlier research, it was found that the excess quantitative workload were the most powerful stressor has a relationship with mental emotional disorders among the workers [24]. Related to career development, precarious employment status also was one of the predictors of arise CMD and as work stressor [25]. These previous study result statement are possible to be applied in this context because based on the policy of the Minister of Health of Republic of Indonesia that the NSI assignment period is only for 2 (two) years with evaluation at the first year. Thus, this problems causing the impact of psychological disturbances on NSI personnel after a period of work that has need to re-apply or look for a new job again.

\section{CONCLUSION}

The trends prevalence of CMD in remote health professional in NSI program was $21.4 \%$. Some of health professionals is expected to be able to adjust to his work and work location in remote areas and if they unable to adjust it might have prolong emotional mental disorder. Most of the factors that cause CMD in NSI are related to work. These findings emphasize the importance of the mental health of health workers and through study, mental health conditions among NSI were not good, it suggests that further researches on the characteristics and risks to the dentist should be made. Along with this study reveals the ministry of health is expected to be able to anticipate stressors that may appear on the health workers and give an intervention for the health workers in remote areas in order to get better work conditions and increase their social support at work. Future programs through regular mental health examination as well as coping stress management guidelines for health workers should be provided and more focused in that region both for community and health workers. Establishing a clear job description for NSI also helps overcome this problem.

\section{ACKNOWLEDGMENTS}

The authors express sincere appreciation to the NSI's personnel staff and the Board for 
[13] Rodrigues EP, Rodrigues US, Oliveira L de MM, Laudano RCS, Nascimento Sobrinho CL. Prevalence of common mental disorders in nursing workers at a hospital of Bahia. Rev Bras Enferm. 2014;67(2):296-301.

[14] Afifah KA, Anganthi NRN, Asyanti S. [Mental health literation in health workers]. [tesis]. Solo: Universitas Muhammadiyah Surakarta; 2016.

[1] Goldberg D. A bio-social model for common mental disorders. Acta Psychiatr Scand Suppl. 1994;385:66-70.

[2] Braga LC de, Carvalho LR de, Binder MCP. [Working conditions and common mental disorders among primary health care workers from Botucatu, São Paulo State]. Cien Saude Colet. 2010;15 Suppl 1:1585-96.

[3] Ruitenburg MM, Frings-Dresen MH, Sluiter JK. The prevalence of common mental disorders among hospital physicians and their association with self-reported work ability: a cross-sectional study. BMC Health Serv Res. 2012;12(1):292.

[4] Skapinakis P, Bellos S, Koupidis S, Grammatikopoulos I, Theodorakis PN, Mavreas V. Prevalence and sociodemographic associations of common mental disorders in a nationally representative sample of the general population of Greece. BMC Psychiatry. 2013;13(1):163.

[5] Carvalho CN, Melo-Filho DA de, Carvalho JAG de, Amorim ACG de. [Prevalence and factors associated with commom mental disorders in medical and multiprofessional health residents]. J Bras Psiquiatr. 2013;62(1):38-45.

[6] Ministry of Health Republic of Indonesia. [Basic Health Survey Report 2018]. Jakarta; 2018.

[7] Ministry of Health Republic of Indonesia. [Basic Health Survey Report 2013]. Jakarta; 2013.

[8] Widianti D, Dewi C. [Impact of work stress on musculoskeletal disorder disorders in hospital project workers]. In: The Role of Occupational Medicine in Keeping The Workers in Their Job. Jakarta: Perhimpunan Spesialis Kedokteran Okupasi Indonesia; 2018. p. 26-7.

[9] Opie T, Lenthall S, Dollard MF. Occupational Stress in the Remote Area Nursing Profession. In: Handbook of Stress in the Occupations. Edward Elgar Publishing; 2011. p. 16-30.

[10] Tomasi E, Facchini LA, Piccini RX, Thumé E, Silveira DS da, Siqueira FV, et al. [Epidemiological and socio-demographic profile of primary care workers in the South and Northeast of Brazil]. Cad Saude Publica. 2008;24 Suppl 1:S193-201.

[11] Idaiani S, Lubis A, Pradono J, Suriani O. [Identification of stress risk factors and sociodemographic variables based on Surkesda Nanggroe Aceh Darussalam 2006]. Media Penelit dan Pengemb Kesehat. 2007;17(3).

[12] Knuth BS, Silva RA da, Oses JP, Radtke VA, Cocco RA, Jansen K, et al. Mental disorders among health workers in Brazil. Cien Saude Colet. 2015;20(8):2481-8.
[15] Kennedy B, Patterson L, White S. Well-being in the rural and remote health workplace: What's happening out there? In: 7th National Rural Health Conference. Hobbart; 2003.

[16] Kustiawan R, Anshori FF. [Overview of anxiety level of parents of children with seizures hospitalization fever in the hospital dr. Soekardjo Kota Tasikmalaya]. J Kesehat Bakti Tunas Husada. 2015;13(1).

[17] AlFahhad NM. Prevalence and factors associated with depression among health care workers in National Guard Hospital in Riyadh, KSA. Int J Med Dev Ctries. 2018;2(3):92-6.

[18] Novianty AS, Budiningsih S, Sjarif H. [Occupational stress and its relation with the tendency to develop mental emotional disorder among nurses who directly involved in mentally ill patients' care in a mental hospital in Jakarta]. J Indon Med Assoc. 2018;68(1):12-7.

[19] Surilena S, Kurniawan SL, Ismail RI. [The association between job stress and psychopathology at Atma Jaya Hospital nurses]. Damianus J Med. 2015;14(1):28-36.

[20] Ludermir AB, Melo Filho DA de. [Living conditions and occupational organization associated with common mental disorders]. Rev Saude Publica. 2002;36(2):213-21.

[21] Mutiah C, Malaka T, Sitorus RJ. Risk factor analysis of occurrence of stress at dentists in Palembang City. Sriwij J Med. 2019;2(1):262-7.

[22] Abdullah S, Saeed T. Comparison of role stressors, job satisfaction and turnover intensions of dentists working in public and private sectors. Pakistan Oral Dent J. 2013;33(3).

[23] Opie T, Dollard M, Lenthall S, Wakerman J, Dunn S, Knight $S$, et al. Levels of occupational stress in the remote area nursing workforce. Aust $\mathrm{J}$ Rural Health. 2010;18(6):235-41.

[24] Wahyuni. [Relationship analysis between work stresses with emotional mental disorders in workers in the crude palm oil processing factory PT. Asianagro Agung Jaya Kota Tanjungbalai 2013]. [tesis]. Medan: Universitas Sumatera Utara; 2013.

[25] Lima MS, Beria JU, Tomasi E, Conceicao AT, Mari JJ. Stressful Life Events and Minor Psychiatric Disorders: An Estimate of the Population Attributable Fraction in a Brazilian Community-Based Study. Int J Psychiatry Med. 1996;26(2):211-22. 